\title{
BMJ Open Impact of mammography screening programmes on breast cancer mortality in Switzerland, a country with different regional screening policies
}

\author{
Christian Herrmann, ${ }^{1,2,3}$ Penelope Vounatsou, ${ }^{2,3}$ Beat Thürlimann, ${ }^{4,5}$ \\ Nicole Probst-Hensch, ${ }^{2,3}$ Christian Rothermundt, ${ }^{4}$ Silvia Ess ${ }^{1}$
}

To cite: Herrmann C, Vounatsou P, Thürlimann B, et al. Impact of mammography screening programmes on breast cancer mortality in Switzerland, a country with different regional screening policies. BMJ Open 2018;8:e017806. doi:10.1136/ bmjopen-2017-017806

- Prepublication history and additional material for this paper are available online. To view these files, please visit the journal online (http://dx.doi. org/10.1136/bmjopen-2017017806).

Received 7 June 2017 Revised 26 January 2018 Accepted 2 February 2018

Check for updates

${ }^{1}$ Cancer Registry St GallenAppenzell, Cancer League Eastern Switzerland, Sankt Gallen, Switzerland

${ }^{2}$ Department of Public Health, University of Basel, Basel,

Switzerland

${ }^{3}$ Epidemiology and Public Health, Swiss Tropical and Public Health Institute, Basel, Switzerland

${ }^{4}$ Department of Internal Medicine, Division OncologyHaematology, Kantonsspital Sankt Gallen, St Gallen, Switzerland

${ }^{5}$ Breast Centre St Gallen, Cantonal Hospital, St Gallen, Switzerland

Correspondence to Dr Christian Herrmann; christian.herrmann@kssg.ch

\section{ABSTRACT}

Introduction In the past decades, mortality due to breast cancer has declined considerably in Switzerland and other developed countries. The reasons for this decline remain controversial as several factors occurred almost simultaneously, including important advances in treatment approaches, breast cancer awareness and the introduction of mammography screening programmes in many European countries. In Switzerland, mammography screening programmes (MSPs) have existed in some regions for over 20 years but do not yet exist in others. This offers the possibility to analyse its effects with modern spatiotemporal methodology. We aimed to assess the spatiotemporal patterns and the effect of MSPs on breast cancer mortality. Setting Switzerland.

Participants The study covers breast cancer deaths of the female population of Switzerland during the period 1969-2012. We retrieved data from the Swiss Federal Statistical Office aggregated on a small-area level. Design We fitted Bayesian hierarchical spatiotemporal models on death rates indirectly standardised by national references. We used linguistic region, degree of urbanisation, duration of population-based screening programmes and socioeconomic index as covariates. Results In Switzerland, breast cancer mortality in women slightly increased until 1989-1992 and declined strongly thereafter. Until 2009-2012, the standardised mortality ratio declined to $57 \%$ (95\% Cl $54 \%$ to $60 \%$ ) of the 1969-1972 value. None of the other coefficients of the spatial regressions had a significant effect on breast cancer mortality. In 2009-2012, no region had significantly elevated or reduced breast cancer mortality at $95 \%$ credible interval level compared with the national mean.

Conclusion There has been a strong reduction of breast cancer mortality from the 1990s onwards. No important spatial disparities were observed. The factors studied (urbanisation, language, duration of population-based MSP and socioeconomic characteristics) did not seem to have an influence on them. Low participation rates and opportunistic screening use may have contributed to the low impact of MSPs.

\section{INTRODUCTION}

In Switzerland, breast cancer is the most frequently diagnosed cancer in women, ${ }^{1}$ it is
Strengths and limitations of this study

- A modern Bayesian spatial model was used to improve estimation of an unstable rate by 'borrowing' strength from its neighbours.

- The model is capable of assessing the significance of risk factors while also taking the geographical correlation into account.

- Switzerland with its homogeneous health system and different regional screening policies provides an ideal setting for assessing the impact of populationbased mammography screening programmes.

- Data on the geographical differences in opportunistic screening use and therefore overall screening participation are not available, where opportunistic screening use is estimated to be high and programme participation less than $50 \%$.

- The ecological study design does not allow an assessment of the combined impact of participation in and type (programme vs opportunistic) of mammography screening.

the leading cause of cancer-related deaths ${ }^{2}$ and of premature mortality for Swiss women. ${ }^{3}$ Mortality due to breast cancer has declined considerably in the past decades in Switzerland and other developed countries. ${ }^{4}$ The reasons for the decline remain controversial because several factors including important advances in treatment approaches, breast cancer awareness and the introduction of mammography screening programmes in many European countries occurred almost simultaneously.

Some randomised controlled studies $^{5}$ have demonstrated a breast cancer mortality reduction of $20 \%$ for women invited for breast cancer screening. However, they were conducted in the 1970 s to 1980 s. Since then, many advances in therapies have been made and adopted ${ }^{6}$ so that some authors doubt that the difference would persist under present conditions. Therefore, often used historical 
prescreening control groups are not best suited to disentangle these effects. Autier et $a l^{7}$ compared countries in Europe but a criticism was that different countries may have different health systems. Kalager et al used comparison groups in Norway and showed that only a third of the total mortality reduction could be attributed to mammography screening. However, a short observation period was used. Olsen et a ${ }^{\theta}$ confirmed these results in principle with the same data but with a somewhat longer follow-up duration. In addition, in a setting where voluntary screening is assumed to be high, it is unknown what the effect an organised screening programme would be for the population as a whole.

In Switzerland, with its homogenous health system, these pitfalls can be avoided. Switzerland is a small confederation of 26 relatively autonomous states called cantons with somewhat low inequalities ${ }^{10}$ and many health and cancer-related resources. ${ }^{11-13}$ Although the healthcare system is homogeneous in providing universal and rapid access to and use of almost unlimited healthcare resources, some healthcare policies are developed at the cantonal level; in particular, the decision to initiate a population-based mammography screening programme. These programmes were implemented in Switzerland at different times over the past two decades. The first Swiss mammography pilot programme was established in 1993 in the French-speaking canton of Vaud. However, it was only in 2010 that the first organised programme in a German-speaking canton (St Gallen) started.

In breast cancer incidence, cantonal differences are well known and have been attributed to the differential use of opportunistic or organised mammography screening. ${ }^{14}$ In addition, considerable differences in health and health-related behaviour that affect the risk of breast cancer, including alcohol intake and a healthy diet, have been reported for the Swiss language regions, ${ }^{15} 16$ as well as differences in the age at first childbirth and number of children born to a mother. ${ }^{17}$ Differences in access to mammography screening and in lifestyle may be reflected in spatiotemporal differences in both breast cancer incidence and mortality, whereas only the latter will reflect the management of breast cancer.

In contrast, breast cancer mortality studies in Switzerland showed contradictory results. Bulliard et $a l^{18}$ observed a steeper decrease from 1980 to 2002 in 55-74year olds in French-speaking regions where population-based mammography screening started earlier. In a recent study, ${ }^{19}$ we presented the spatiotemporal trends of female gender-related cancer mortality in Switzerland by age group. The geographical differences found were small. We observed a differential decline in breast cancer mortality by age. The decline was highest in women younger than 50 and lower in women 75 or older. A similar pattern was observed in other European countries ${ }^{4}$ and attributed to early detection by mammography and to improved treatment. ${ }^{20-22}$ However, it was not clear to what extent improvements in survival could have affected the age at death. It was difficult to evaluate a shift of deaths into the next higher age group and the influence of screening programmes based on using fixed age groups rather than cohorts.

In the present study, we aimed to assess the spatiotemporal patterns in breast cancer mortality and specifically the effect of population-based mammography screening programmes on it. We corrected for urbanisation for which a mortality gradient was described ${ }^{23}$ and additionally for area-based socioeconomic factors, which may have influenced results in the previous study.

\section{METHODS}

\section{Data sources}

The Swiss Federal Statistical Office provided data on female breast cancer mortality, electronically available for the period of 1969-2012. The anonymised data included sex, age, year of birth and death for each individual, nationality, municipality of residence, the cause of death and comorbidities. The cause of death and comorbidities were coded centrally from death certificates using the eighth revision of the International Classification of Diseases (ICD) for deaths until 1994, and the 10th revision for deaths that occurred afterwards. The transition to the 10th revision of the ICD was accompanied by changes in death certificate coding practices (priority rules). We used age and cancer site-specific correction factors as proposed by Lutz $e t a l^{24}$ for the death counts. We included all cases coded with main causes of death being cancer of the female breast (ICD-10 C50.0C50.9). According to federal regulations, mortality data excluding a person's identifying information can be used in epidemiological studies without additional ethics committee approval.

The administrative borders of Swiss municipalities define the smallest geographical unit for which data were available. There are around 2500 municipalities in the country with a median population of 740 inhabitants in 1970 and 1150 in 2010.

Aggregated population data by age and area unit were extracted from the census that takes place in Switzerland every 10 years. The last census was conducted in 2010 . Because of missing detailed intercensal population data, we aggregated the mortality data in five 4-year periods around the census years, that is, 1969-1972, 1979-1982, 1989-1992, 1999-2002 and 2009-2012, in which population was assumed to be constant and identical to the census year.

From the same source, we retrieved data on language region (German, French and Italian and Romansh) and urbanisation (rural/urban). We obtained information on population-based screening programmes from the Swiss Federation of Cancer Screening Programmes ${ }^{25}$ and categorised their duration in the census years into 'no programme', ' $0-4$ years' and ' $5+$ years'. Data on socioeconomic position by municipality were provided by the Swiss National Cohor ${ }^{26}$ based on the census data of 2000 . 
Table 1 Observed numbers of female breast cancer deaths and mortality rates per 100000 PY by period and municipality characteristics. The total numbers before 1994 include the correction factors

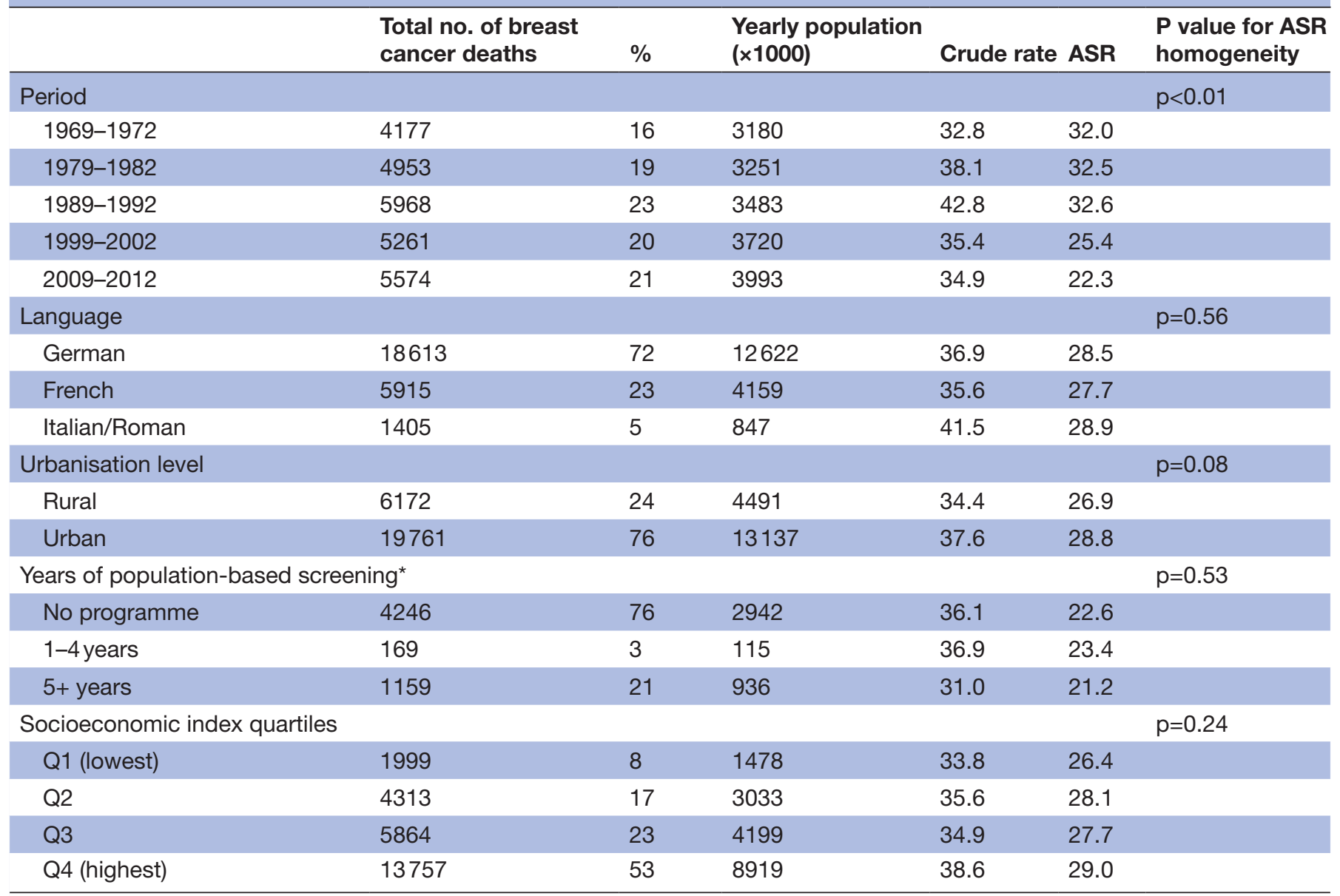

*Only for the period 2009-2012, length of screening refers to the year 2010.

ASR, Age Standardised mortality Rate; PY, Person Years.

Table 1 shows the observed number of deaths and mortality rates for each of the covariates.

\section{Statistical methods}

As a small area geographical unit, we used the municipality borders as of 2012. We used municipality transition protocols from the Federal Statistical Office to align all data to this structure.

We investigated mortality for all ages combined in a spatial and a non-spatial model, one time for the five time periods from 1969 to 2012 to assess possible non-linear time trends and another time only for the period of 2009-2012.

For the spatial model, we used the Bayesian hierarchical spatiotemporal Poisson model formulations as described in Herrmann $e t a l,{ }^{19}$ fitted on the number of deaths aggregated by small area and year, with the mean being equal to the product of the expected death count and age-standardised mortality rate. The indirect standardisation used 5-year age intervals. Expected mortality counts for each small area and year were obtained from the study population using nationwide age-specific mortality rates, once for all periods and again only for the period of 2009-2012.
The small area-specific random effects were modelled via conditional autoregressive models to filter out the noise and highlight the observed patterns. The deviance information criterion (DIC) was used to select the regression model from Poisson, zero-inflated Poisson and negative binomial regression models. The DIC was lowest with the Poisson regression model.

We accounted for differences that were influenced by linguistic region, life in rural or urban areas, screening programme duration and socioeconomic position. These analyses are used to indicate whether there are significant differences in cancer mortality for each of the above covariates, assessed by $95 \%$ Bayesian Credible Intervals.

\section{Patient involvement}

No patients were involved in this study.

\section{RESULTS}

In Switzerland, more than 61000 women died from breast cancer between 1969 and 2012. Table 2 presents the results of the regressions including all time periods 
Table 2 Spatiotemporal model estimates of age-specific breast cancer mortality in Switzerland from the 1969-1972 period to the 2009-2012 period. Bold values denote agestandardised mortality ratio significantly different from 1. Spatial variation (SD of spatial random effects): a value of 0 means that there is no spatial correlation

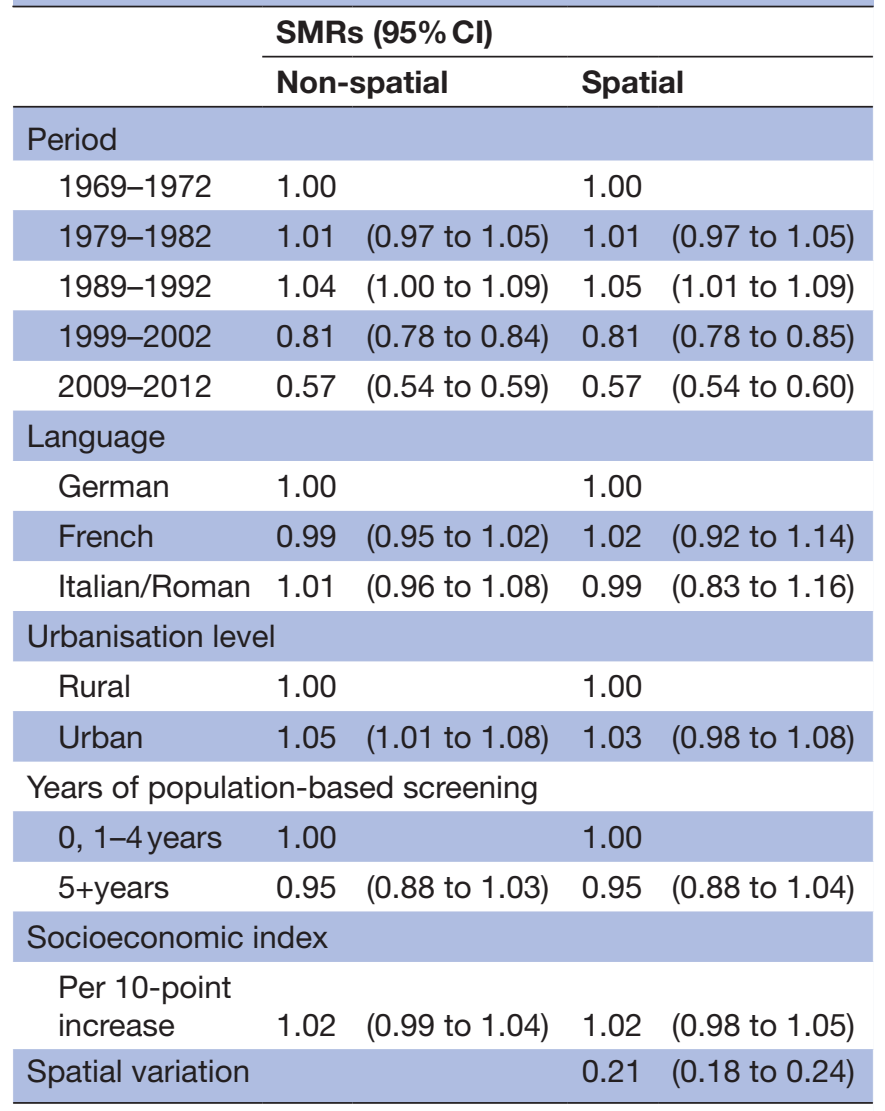

SMR, standardised mortality ratio.

and time trends. In Switzerland, breast cancer mortality in women slightly increased until the 1989-1992 period and has declined strongly since. Until the most recent period (2009-2012), the SMR has fallen to 57\% of the 1969-1972 period's value, both in the non-spatial and the spatial models. The trends and geographical differences are visualised in figure 1 .

From the covariates studied, only the year of death and the urbanisation level in the non-spatial model had a significant impact when investigating all periods. An urban environment was associated with a $5 \%$ elevated SMR (3\% in the spatial model) compared with a rural environment.

Limiting the analysis to the period of 2009-2012, none of the regression factors had a significant effect on breast cancer mortality (table 3 ).

Most SMR ratios of the non-spatial and the spatial model showed nearly identical values. The length of a screening programme and the French language region showed slightly higher values, but the differences were not significant.

In the 2009-2012 period, no region had a significantly higher or lower breast cancer mortality rate at $95 \%$ CI

\section{Time trends in spatial differences in breast cancer mortality}
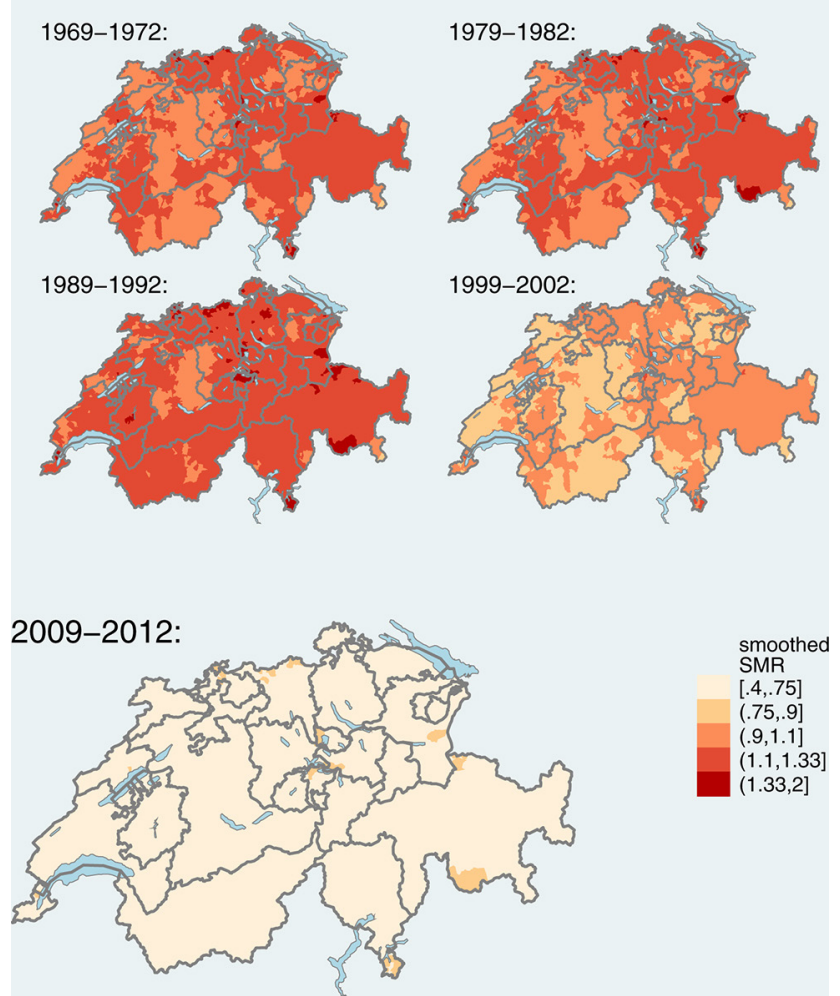

Figure 1 Development of age-standardised breast cancer mortality and spatial differences therein among time. Values are calculated and smoothed in relation to the all-period combined mortality. Darker colours represent a higher mortality for the specific age structure and population in that area and time period. SMR, standardised mortality ratio.

level compared with the national mean (figure 2). A map with covariate-adjusted smoothed SMR values is not shown because there was no information gain. The covariates are not significant and the geographical patterns are the same as for the smoothed SMR values.

The socioeconomic index value for the municipalities ranged from 28 to 85 , where $25 \%$ of municipalities were below $55 \%$ and $25 \%$ above 66 .

\section{DISCUSSION}

In the past decades, breast cancer mortality has nearly halved in Switzerland when considering all ages together. This trend, including the shift from increasing to decreasing rates around the period of 1989-1992, has been observed in several other European countries. ${ }^{4}$ Although significant spatial differences in breast cancer incidence are well described for Switzerland, we have not found any significant differences in breast cancer mortality in any of the periods studied. We have not observed any general significant differences between regions classified by duration of screening programmes, urbanisation, language and socioeconomic position. In addition, when limiting the analysis to the most recent period (2009-2012), none 
Table 3 Spatiotemporal model estimates of agestandardised breast cancer mortality in Switzerland in the 2009-2012 period. Bold values denote age-standardised mortality ratios significantly different from 1

\begin{tabular}{|c|c|c|c|}
\hline & \multicolumn{3}{|l|}{ SMRs $(95 \% \mathrm{Cl})$} \\
\hline & Non-spatial & \multicolumn{2}{|c|}{ Spatial } \\
\hline \multicolumn{4}{|l|}{ Language } \\
\hline German & 1.00 & 1.00 & \\
\hline French & $1.00 \quad(0.86$ to 1.15$)$ & 1.03 & (0.81 to 1.33 ) \\
\hline Italian/Roman & 1.01 (0.87 to 1.16$)$ & 1.00 & (0.68 to 1.37$)$ \\
\hline \multicolumn{4}{|l|}{ Urbanisation level } \\
\hline Rural & 1.00 & 1.00 & \\
\hline Urban & 0.97 (0.89 to 1.06$)$ & 0.97 & (0.89 to 1.07 ) \\
\hline \multicolumn{4}{|c|}{ Years of population-based screening } \\
\hline $0,1-4$ years & 1.00 & 1.00 & \\
\hline $5+$ years & 0.95 (0.82 to 1.11$)$ & 0.99 & (0.78 to 1.23 ) \\
\hline \multicolumn{4}{|c|}{ Socioeconomic index } \\
\hline $\begin{array}{l}\text { Per 10-point } \\
\text { increase }\end{array}$ & 1.03 (0.97 to 1.09$)$ & 1.03 & (0.95 to 1.10$)$ \\
\hline Spatial variation & & 0.29 & (0.24 to 0.35$)$ \\
\hline
\end{tabular}

SMR, standardised mortality ratio.

of the factors are significant. In fact, at $95 \% \mathrm{CI}$, none of the regions have a significantly elevated or reduced breast cancer mortality compared with the national mean.

There are several factors that explain why the significant differences in incidence do not translate into corresponding mortality differences. Most importantly, risk factors such as health and health-related behaviour that are reported to be different for the language regions ${ }^{16}$ affect incidence but are not necessarily linked to mortality. ${ }^{27}$ That is, while a temporary increase in the use of hormone replacement therapy has led to an increase in breast cancer incidence, many of those tumours have a favourable prognosis and might have influenced breast cancer mortality only marginally. ${ }^{28}$ Accordingly, the French language region, despite earlier implementation

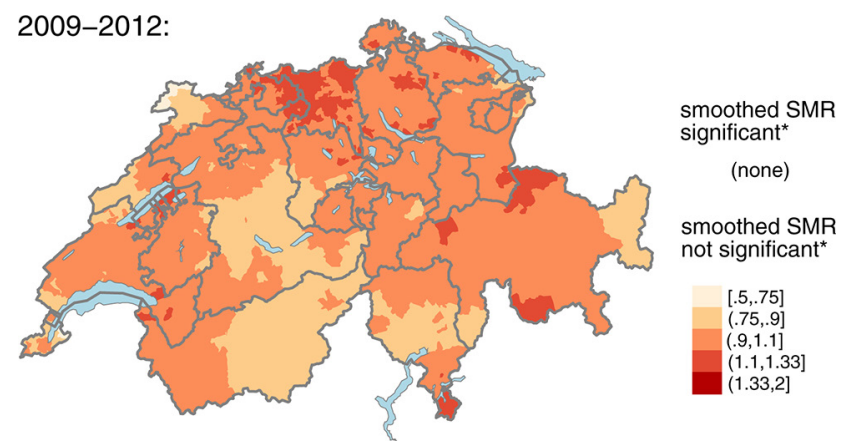

Figure 2 Geographical differences in age-standardised breast cancer mortality in 2009-2012. * Significance is denoted as values significantly different at $95 \% \mathrm{Cl}$ from 1 , the national mean. SMR, standardised mortality ratio. of mammography screening programmes, does not show a relevant impact on breast cancer mortality in our study.

Because screening has been identified as a potential source of mortality reduction, ${ }^{21}$ we also included data on population-based screening programme duration. However, our study did not show a significant effect on mortality on the population level. The reasons for this are probably manifold and may include factors such as screen-detected cancers being mainly of low stage, many women having not participated in the screening programmes or having chosen to undergo opportunistic screening. In addition, the effect of advances in diagnosis and therapy on mortality is quite strong and may have outweighed benefits from population-based screening programmes, as suggested by Autier et $a l .{ }^{29}$ Moreover, the level of opportunistic screening in Switzerland has been described to be quite high, ${ }^{30}$ but data on the geographical differences in opportunistic screening use, and therefore overall screening participation, are not available. Data on participation in population-based screening programmes are published in a national monitoring report showing that participation rates of the programmes are close to the combined mean of $47.8 \% .{ }^{31}$ The ecological study design does not allow the assessment of the combined impact of participation in and type (programme vs opportunistic) of mammography screening or the impact of stage of tumour at diagnosis and mortality at an individual level. For the above reasons, the interpretability with regard to screening is limited. In addition, we had to group into 0-4 years and $5+$ years of screening, which was done to avoid overfitting issues. There are only a few regions that are in close proximity to each other with $10+$ years of screening in the 2009-2012 period only (see online supplementary figure A1).

The present study is an in-depth analysis of our previous study, ${ }^{19}$ focusing on breast cancer mortality using an additional year of more recent data. We were also interested in the effects on the population as a whole. The applied methodology of age standardisation suits this by taking advantage of the actual age structure rather than of a standard population.

The non-significant fixed effect of socioeconomic position is in line with the results of Panczak et al..$^{32}$ The additional correction served the disentanglement of affluence from the urbanisation parameter-which is connected with access to medical services-and further possible distortions. $^{33}$

A strength of Bayesian spatial models is their 'smoothing' or improvement of estimation of an unstable rate by 'borrowing' strength from its neighbours. ${ }^{34}$ These models can also assess the significance of risk factors, taking into account the geographical correlation and are able to show spatial patterns after adjusting for geographical differences in certain risk factors. By adding a time dimension, Bayesian spatiotemporal models indicate changes of geographical patterns over time and determine how a disease evolves in different regions and different groups of the population (age, language or 
affluence groups). These models have provided a stateof-the-art modelling approach over the last 15 years for assessing spatio-temporal patterns and trends. We have not observed that coefficients in our analysis have shrunk towards zero when including geographical correlation as hypothesised by Hodges and Reich. ${ }^{35}$ In fact, in the spatial model for the 2009-2012 period, the impact of the French language region is 1.03 compared with 1.00 in the non-spatial model. However, we have included the results of the non-spatial models as well.

\section{CONCLUSION}

There has been a strong reduction of breast cancer mortality from the 1990s onwards. Geographical differences are present, but at a moderate level with no significant differences in the overall mean. In addition, they are not explained by the duration of population-based screening programmes, socioeconomic position, urbanisation and language region. Low participation rates and opportunistic screening use may have contributed to the low impact of mammography screening programmes. Continuous evaluation of geographical patterns of breast cancer mortality using modern spatiotemporal methodology is necessary for evaluating the efficacy of programmes.

Contributors PV, SE conceived of the study. $\mathrm{CH}$ carried out the analysis and data acquisition. $\mathrm{CH}, \mathrm{SE}, \mathrm{PV}$ contributed to the analysis of the data and the writing of the manuscript. CH, PV, BT, NPH, CR and SE contributed to interpretation of the findings and critically revised the manuscript. All authors read and approved the final manuscript.

Funding $\mathrm{CH}$ was supported by the Cancer League Eastern Switzerland and $\mathrm{CH}$ and PV were supported by a grant of the Swiss National Science Foundation with the number 32003B_135769.

Disclaimer The funders had no role in the study design, data collection and analysis, decision to publish or preparation of the manuscript.

Competing interests None declared.

Patient consent Detail has been removed from this case description/these case descriptions to ensure anonymity. The editors and reviewers have seen the detailed information available and are satisfied that the information backs up the case the authors are making.

Provenance and peer review Not commissioned; externally peer reviewed.

Data sharing statement All data are publically available from the sources stated in the Methods section. Statistical code is available from the corresponding author.

Open Access This is an Open Access article distributed in accordance with the Creative Commons Attribution Non Commercial (CC BY-NC 4.0) license, which permits others to distribute, remix, adapt, build upon this work non-commercially, and license their derivative works on different terms, provided the original work is properly cited and the use is non-commercial. See: http://creativecommons.org/ licenses/by-nc/4.0/

(c) Article author(s) (or their employer(s) unless otherwise stated in the text of the article) 2018. All rights reserved. No commercial use is permitted unless otherwise expressly granted.

\section{REFERENCES}

1. Ferlay J, Soerjomataram I, Ervik M, et al. GLOBOCAN 2012 v1.0, Cancer Incidence and Mortality Worldwide. Secondary GLOBOCAN 2012 v1.0, Cancer incidence and mortality worldwide. 2013. http:// globocan.iarc.fr
2. NICER (National Institute for Cancer Epidemiology and Registration). Secondary national institute for cancer epidemiology and registration. 2017. http://www.nicer.org

3. Savidan A, Junker C, Cerny T, et al. Premature deaths in Switzerland from 1995-2006: causes and trends. Swiss Med Wkly 2010;140:w13077.

4. World Health Organization (WHO). WHO Cancer mortality database. Secondary WHO Cancer mortality database. 2015. http://www-dep. iarc.fr/WHOdb/WHOdb.htm

5. Marmot MG, Altman DG, Cameron DA, et al. The benefits and harms of breast cancer screening: an independent review. $\mathrm{Br} J$ Cancer 2013;108:2205-40.

6. Ess S, Savidan A, Frick H, et al. Geographic variation in breast cancer care in Switzerland. Cancer Epidemiol 2010;34:116-21.

7. Autier P, Boniol M, Gavin A, et al. Breast cancer mortality in neighbouring European countries with different levels of screening but similar access to treatment: trend analysis of WHO mortality database. BMJ 2011;343:d4411.

8. Kalager M, Zelen M, Langmark F, et al. Effect of screening mammography on breast-cancer mortality in Norway. N Engl J Med 2010;363:1203-10.

9. Olsen AH, Lynge E, Njor SH, et al. Breast cancer mortality in Norway after the introduction of mammography screening. Int $\mathrm{J}$ Cancer 2013;132:208-14.

10. Organisation for Economic Co-operation and Development (OECD). OECD review of health systems. Switzerland: WHO, 2006.

11. Department of Health Systems Financing HSS. 2011 WHO Global health expenditure atlas. Secondary 2011 WHO Global health expenditure atlas. 2013. http://www.who.int/nha/atlas.pdf

12. Jönsson B, Wilking N. A global comparison regarding patient access to cancer drugs. Ann Oncol 2007;18(Suppl 3):iii1-77.

13. Jonsson B, Wilking N. A pan-European comparison regarding patient access to cancer drugs. Stockholm: Karolinska Institutet in collaboration with Stockholm School of Economics, 2005.

14. Wanner P, Raymond L, Bouchardy C. Geographical disparities in self-reported use of mammography and breast self-examination according to the swiss health survey. Ann Oncol 2001;12:573-4.

15. Calmonte R, Galati-Petrecca M, Lieberherr R, et al. Gesundheit und gesundheitsverhalten in der Schweiz 1992-2002: schweizerische gesundheitsbefragung. Neuchâtel: Bundesamt für Statistik, 2005.

16. Lieberherr R, Marquis J-F, Storni M, et al. Gesundheit und gesundheitsverhalten in der Schweiz 2007 - schweizerische gesundheitsbefragung. Neuchâtel: Bundesamt für Statistik (BFS), 2010.

17. Swiss Federal Statistical Office. STAT-TAB: Die interaktive Statistikdatenbank. Secondary STAT- TAB: Die interaktive Statistikdatenbank. 2017. http://www.pxweb.bfs.admin.ch/

18. Bulliard JL, La Vecchia C, Levi F. Diverging trends in breast cancer mortality within Switzerland. Ann Oncol 2006;17:57-9.

19. Herrmann C, Ess S, Thürlimann B, et al. 40 years of progress in female cancer death risk: a Bayesian spatio-temporal mapping analysis in Switzerland. BMC Cancer 2015;15:666.

20. Jemal A, Bray F, Center MM, et al. Global cancer statistics. $C A$ Cancer J Clin 2011;61:69-90.

21. Berry DA, Cronin KA, Plevritis SK, et al. Effect of screening and adjuvant therapy on mortality from breast cancer. N Engl J Med 2005;353:1784-92.

22. Levi F, Bosetti C, Lucchini F, et al. Monitoring the decrease in breast cancer mortality in Europe. Eur $J$ Cancer Prev 2005;14:497-502.

23. Schüler G, Bopp M, eds. Atlas der krebsmortalität in der schweiz 1970-1990. Basel: Birkhäuser Verlag, 1997.

24. Lutz JM, Pury P, Fioretta G, et al. The impact of coding process on observed cancer mortality trends in Switzerland. Eur J Cancer Prev 2004;13:77-81.

25. Swiss Cancer Screening. Schweizerischer verband der krebsfrüherkennungsprogramme. Secondary schweizerischer verband der krebs-früherkennungsprogramme. 2015. http://www. swisscancerscreening.ch/

26. SNC Swiss National Cohort. Secondary Swiss national cohort. 2015. http://www.swissnationalcohort.ch/

27. Barnett GC, Shah M, Redman K, et al. Risk factors for the incidence of breast cancer: do they affect survival from the disease? J Clin Oncol 2008;26:3310-6.

28. Verkooijen HM, Bouchardy C, Vinh-Hung V, et al. The incidence of breast cancer and changes in the use of hormone replacement therapy: a review of the evidence. Maturitas 2009;64:80-5.

29. Autier P, Boniol M, La Vecchia C, et al. Disparities in breast cancer mortality trends between 30 European countries: 
retrospective trend analysis of WHO mortality database. $B M J$ 2010;341:c3620.

30. Chamot E, Charvet Al, Perneger TV. Who gets screened, and where: a comparison of organised and opportunistic mammography screening in Geneva, Switzerland. Eur J Cancer 2007;43:576-84

31. Bulliard J-L, Zwahlen M, Fracheboud J. Monitoring report 2012 der Schweizer Brustkrebsfrüherkennungsprogramme. Bern: Swiss Cancer Screening (SCS), 2016.

32. Panczak R, Galobardes B, Voorpostel M, et al. A Swiss neighbourhood index of socioeconomic position: development and association with mortality. $J$ Epidemiol Community Health 2012:66:1129-36.

33. Clough-Gorr KM, Egger M, Spoerri A. A Swiss paradox? Higher income inequality of municipalities is associated with lower mortality in Switzerland. Eur J Epidemiol 2015;30:627-36.

34. Bernardinelli L, Montomoli C. Empirical bayes versus fully bayesian analysis of geographical variation in disease risk. Stat Med 1992;11:983-1007.

35. Hodges JS, Reich BJ. Adding spatially-correlated errors can mess up the fixed effect you love. Am Stat 2010;64:325-34. 